\title{
Using Sequential Injection Analysis to Improve System and Data Reliability of Online Methods: Determination of Ammonium and Phosphate in Coastal Waters
}

\author{
Carsten Frank ${ }^{1,2}$ and Friedhelm Schroeder ${ }^{1}$ \\ ${ }^{1}$ GKSS Research Centre, Institute for Coastal Research, Max-Planck-Strasse, 21502 Geesthacht, Germany \\ ${ }^{2}$ University of Lueneburg, 21332 Lueneburg, Germany
}

Received 16 October 2006; Accepted 18 December 2006

This article summarises the advantages of the sequential injection analysis (SIA) for the online determination of nutrients in coastal waters. It concentrates on techniques to improve the reliability of the gained data by continuously monitoring one or more standards and on the advantages of online standard additions and offline determination of manually collected samples with the online SIA system. These measures are advantageous during method development and validation and can be used to verify the system performance on a regular base to reduce the amount of erroneous results. No changes in the flow system are necessary and the sample throughput is only slightly reduced. These techniques have been applied to a SIA system which is able to simultaneously determine ammonium and phosphate at a rate of more than 100 samples per hour each and detection limits $(3 \sigma)$ of $0.06 \mu \mathrm{M}$ and $0.05 \mu \mathrm{M}$. Results from a campaign in summer 2005 are shown.

Copyright ( 92007 C. Frank and F. Schroeder. This is an open access article distributed under the Creative Commons Attribution License, which permits unrestricted use, distribution, and reproduction in any medium, provided the original work is properly cited.

\section{INTRODUCTION}

Online methods are analytical methods aimed for the direct and fast determination of analytes. They integrate-or are connected to-sampling and sample pretreatment system which can deliver fresh drawn samples directly to the analytical system. Such systems are used to either avoid sample storage and all problems connected to it [1-8], or they are used to gain analytical results as fast as possible while monitoring fast changing systems (e.g., as regulation parameters in bioreactors). Online sampling and analysis systems are usually more complex and expensive than manual sampling, sample pretreatment, and determination. However, in many cases online systems are more suitable than manual approaches, especially if large amounts of samples have to be taken and analysed or the contamination risk during sample storage and transport is too high [9].

Depending on the operational area, online systems have to fulfill different requirements. Systems located in remote sampling stations have to be reliable but not necessarily fast, flexible or mobile. More important are comparability and stability which ideally should be proved by, for example, the automatic determination of standards and spiked samples. Online systems used for shipboard campaigns have to be reliable, fast and mobile. While the mobility of a system is a relative feature, the sensitivity is given by the respective application and the cruise speed of the ship defines the required analysis time. Furthermore, the requirements for the reliability of a shipboard online system is slightly different: these systems are in most cases used for campaigns lasting only several days with a tight schedule. Therefore, the online system must work from the start to the end of the campaign independently of interfering parameters like temperature, wind speed, and wave height. In general, the collected data should be supported by regular calibrations and standard additions. Additionally, it is advantageous to manually collect and pretreat samples and then analyse them with the respective online analyser to eliminate errors due to the online sampling and sample pretreatment system.

A recently developed online sequential injection analysis system (SIA) for the combined determination of ammonium and phosphate $[10,11]$ is used to demonstrate the advantages of the SIA if used in an online arrangement. Especially the use of a programmable syringe pump and a multiport switching valve as an autosampler replacement in addition to their normal functions leads to an improved quality control for the online data. Several campaigns were performed with 
this device of which one transect was selected to underline the applicability of the methods described here.

\section{EXPERIMENTAL}

\subsection{Instrumentation}

The analytical system used here consists of three analytical procedures: sampling, sample pretreatment, and determination. On the research vessel, Ludwig Prandtl, an in-situ pump-which is part of the ship-is used to pump the seawater from an inlet at the bow of the ship to the analyser. The water depth of the inlet is about $1.20 \mathrm{~m}$ below the surface. To minimise the residence time of the sample in the ship's tubing system, high flow rates are generated by discharging the main part of the seawater using a bypass at the end of the pipe. A second pump is used to pump the water through a cross flow filter (Minikros M22M-100-01 N, $0.2 \mu \mathrm{m}$, mixed cellulose ester). The filtrate passes a tee near to the valve (Knauer A1492) of the SIA analyser. The valve itself is a 17port/1-channel type where the central port is connected via a $120 \mathrm{~cm}(0.8 \mathrm{~mm}$ i.d.) holding loop to the syringe pump. The valve was selected due to its high reliability-proven during another project [12] — and its high speed (about 0.2 seconds from port to port). During the whole project with more than five shipboard campaigns and uncounted days in the lab, the seal had to be exchanged only once, and the valve only failed twice due to neglected service (missing grease). Two other valves from different companies were tested and one failed due to unreliable electronics and the other's seal had to be replaced after only five days shipboard campaign. The syringe pump is a standard series CAVRO $\mathrm{xl} 3000$ which is able to perform speed ramps. These configurable speed ramps are especially important to reduce pressure peaks if high pump speeds are chosen. The risk of vacuum conditions in the reaction loop or cuvette during deceleration-which can lead to unwanted air bubbles—can be reduced by selecting appropriate speed ramps.

Two different fluorescence detectors are used in this setup (see Figure 1). A Hitachi F1000 fluorescence spectrometer (ex. $365 \mathrm{~nm}$, emm. $425 \mathrm{~nm}$ ) is used for the determination of ammonium. It is connected to an HP $34401 \mathrm{~A}$ digital multimeter which is used as an analog-to-digital converter. The Hitachi fluorescence spectrometer is connected to the valve via three identical reaction loops $(60 \mathrm{~cm} ; 0.8 \mathrm{~mm}$ i.d. $)$ which are heated using home-made pipe system connected to a Haake DC 50 heating bath. Phosphate is determined via a fluorescence detector (ex. $470 \mathrm{~nm}$, emm. $550 \mathrm{~nm}$ ) provided by IPHT Jena (Germany). It is connected via a reaction loop $(60 \mathrm{~cm} ; 0.8 \mathrm{~mm}$ i.d.) to the valve and uses a digital multimeter with RS232 connection (keithley model 2000) as an analog-to-digital converter. All components (the syringe pump, the valve, the multimeters, and the heating bath) are connected via RS232 to a personal computer which controls the whole setup by scripts written in the python programming language.

The ammonium determination is based on the reaction of o-phthaldialdehyde (OPA) with sodium sulfite and am-

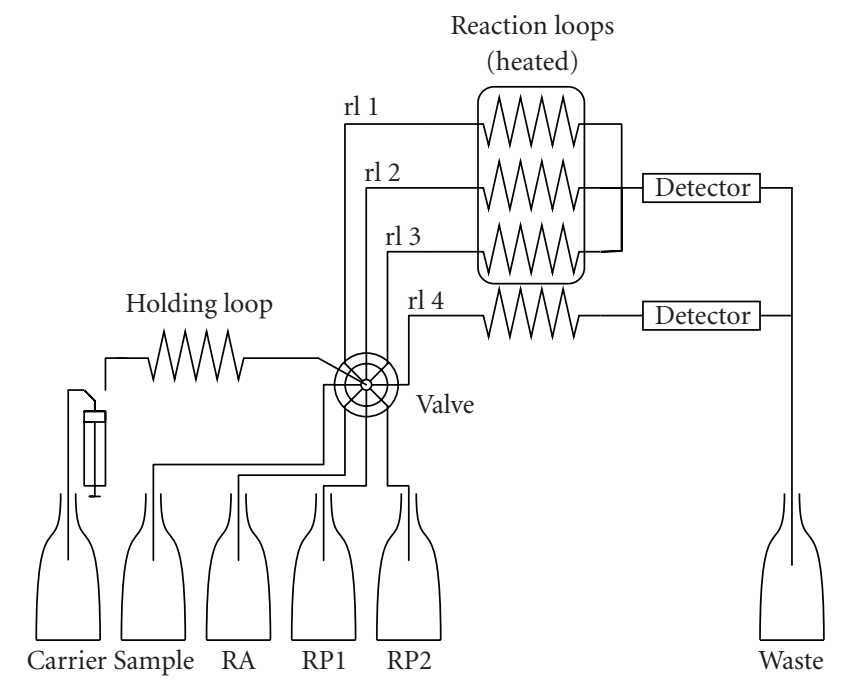

FIGURE 1: Scheme of the SIA used for the fast determination of ammonium and phosphate. RA: reagent for the determination of ammonium, RP1: reagent one for the phosphate determination, RP2: reagent two for the phosphate determination, rl 1-3: reaction loops for the determination of ammonium, $\mathrm{rl}$ 4: reaction loop for the determination of phosphate.

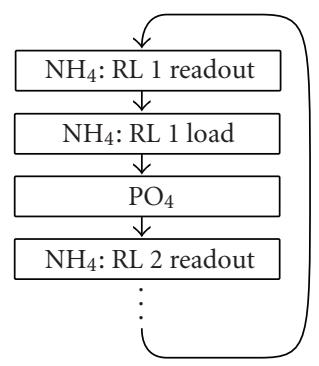

FIGURE 2: Succession of ammonium load, readout, and phosphate determination steps.

monium to a fluorescent product. This reaction needs about 60 seconds at $85^{\circ} \mathrm{C}$ to achieve about $70 \%$ of the maximal fluorescence signal. To achieve a sample throughput higher than 60 samples per hour, at least three reaction loops have to be used in parallel. In the example presented here, three parallel reaction loops were used for the determination of ammonium.

A combined phosphate and ammonium determination starts with an ammonium readout step which is used to determine the fluorescence of the reagent-sample segment. This segment was loaded into the actual reaction loop exactly 60 seconds (three cycles) afore (see Figure 2).

After this readout step, the load step starts with the aspiration of $8.3 \mu \mathrm{l}$ ammonium reagent (RA) followed by $25.0 \mu \mathrm{l}$ sample and $16.7 \mu \mathrm{l}$ RA into the holding loop. The whole reagent-sample segment is then pumped through the valve into the heated part of reaction loop 1. After an idle timewhich is calculated based on a statistical evaluation of prior measurements-25 $\mu \mathrm{l}$ phosphate reagent 1 (RP1) followed by 
$50 \mu \mathrm{l}$ sample, $10 \mu \mathrm{l}$ phosphate reagent 2 (RP2), and $25 \mu \mathrm{l} \mathrm{RP} 1$ are aspirated. This segment is pumped through the valve, reaction loop 4, and the second detector following a certain speed profile. This speed profile ensures sufficient dispersion in the reaction loop, low pump speed in the detector and high speed to flush the system.

This procedure is repeated for all three ammonium reaction loops and then starts again from the beginning until the programme is stopped.

\section{REAGENTS}

All reagents were prepared with fresh-drawn degassed deionised water. Sigma analytical grade chemicals were used, unless otherwise stated.

\subsection{Ammonium}

O-phthaldialdehyde (OPA) stock solution was prepared by dissolving $2 \mathrm{~g}$ of o-phthaldialdehyde (Sigma P-1378) in $25 \mathrm{ml}$ ethanol. This solution has to be shaken for several minutes to achieve complete dissolution. $2 \mathrm{~g}$ of sodium sulfite were dissolved in $250 \mathrm{ml}$ to prepare the sulfite stock solution.

Ammonium reagent (RA). $7.5 \mathrm{~g}$ of disodium tetraborate decahydrate were diluted to $250 \mathrm{ml}$. The solution was stirred until complete dissolution and then transferred into a dark glass bottle. $5 \mathrm{ml}$ of OPA stock solution were added. After stirring $500 \mu \mathrm{l}$ of sulfite stock solution and $0.1 \mathrm{ml}$ of a $30 \%$ Brij (Merck 1.01894) solution were added. After stirring, the solution was left to stand for several hours [10, 13].

Ammonium standard stock solution was $1 \mathrm{~g}\left(\mathrm{NH}_{4}\right) / \mathrm{l}$ from Merck.

\subsection{Phosphate}

Rhodamine stock solution was prepared by dissolving $0.20 \mathrm{~g}$ of rhodamine $6 \mathrm{G}$ in $100 \mathrm{ml}$ water. Molybdate stock solution was made by dissolving $12.8 \mathrm{~g}$ of ammonium heptamolybdate tetrahydrate (Merck, analytical grade) in $100 \mathrm{ml}$ water. To prepare reagent 1 (RP1), $200 \mu \mathrm{l}$ rhodamine 6G stock solution was added to $90 \mathrm{ml}$ water. $500 \mu \mathrm{l}$ 5\% IGEPAL (Polyoxyethylene $(*)$ octylphenyl ether, branched) was added and the solution diluted to $100 \mathrm{ml}$. Reagent 2 (RP2) was prepared by adding $8.45 \mathrm{ml}$ of $30 \%(\mathrm{v} / \mathrm{v})$ hydrochloric acid to about $75 \mathrm{ml}$ of water. Add $4 \mathrm{ml}$ of molybdate stock solution and dilute to $100 \mathrm{ml}$. The reagents RP1 and RP2 were derived from Wei et al. [10, 14].

Phosphate standard stock solution was $1 \mathrm{~g}\left(\mathrm{PO}_{4}\right) / \mathrm{l}$ from Merck.

\section{RESULTS AND DISCUSSION}

While laboratory conditions are usually stable and clean, the conditions at online sampling sites can be less favourable. On a ship, for example, the conditions can be even more inadequate with variations in temperature, vibrations, and high accelerations. Especially spectrometers can be sensitive to vibrations and temperature changes and may therefore have variations in their sensitivity. Other problems may occur due to variations in the ambient temperature which affect the stability of the reagents.

To avoid inconclusive results, a method was established to ensure continuous recording of the performance of the SIA system. One or more standards are prepared and connected to the valve. These standards are determined automatically on a regular base following a certain order. All measured peaks are instantly integrated and continuously displayed in a graph as tentative results. Any deviation from the expected behaviour (compared to former results in the same or similar areas) can be nearly instantly recognised. A second graph displays the raw data from the detector showing the last peaks in detail. This graph is on the one hand checked on a regular basis for irregularities and on the other hand in case that the first graph shows unexpected results. Nearly all problems usually occurring in a SIA system cause an inconsistency in the baseline or peakshape. Most inconsistencies are typical for certain problems and can therefore be used to find the source of a problem more easily. The raw data is also saved on the hard disk of the computer and can be reviewed any time later.

While problems with the SIA system can be almost certainly ruled out by reviewing the stability of the determination of the standards and by consulting the raw data, problems with the sampling or the sample pretreatment system cannot be ruled out this way. The most sensible approach to eliminate these problem sources is to manually collect and pretreat a sample and then connect it to an additional valve port. The determination of this sample is then intergated into the normal SIA programme flow. Using this system, the manually collected sample can be determined contemporary (some minutes later) to the online sample with the same system without interrupting the online determination. In addition to the determination with the online system, a part of this sample can be preserved and determined later with a standardised laboratory method. This eliminates any problems concerning the comparability of the online sample with the manually collected one.

Two more techniques can be used to improve the quality of the gained data. First, online standard addition and sample dilution can be performed by dividing the sample volume into sections with standard and sample. While this procedure is not applicable in all cases (e.g., the volumes of the sections must be large enough to ensure precise dosing and the reaction loop must be long enough to ensure sufficient mixing between sample and standard) and can not replace the manual method due to its imprecision, this procedure is nevertheless useful to monitor the influence of changes of the sample matrix (e.g., marine and river water in coastal areas) to the performance of the method. The second technique to improve data reliability is the application of two different methods in one system. As has been shown by Frank et al. [10], two different analytical methods can be used in one SIA system without interfering each other. This approach can be used to compare two methods for the same analyte without the need for an independent extra analytical system. 


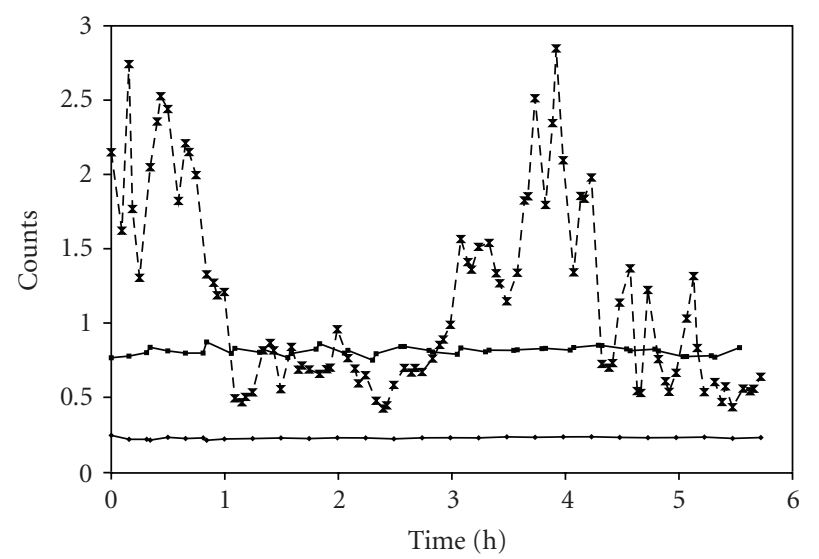

FIgURE 3: Ammonium data gained with the SIA system during a trip from Helgoland to Eidersperrwerk in summer 2005. The results of only one of the three ammonium "channels" (reaction loops) are shown. Blank (bottom line), 3.6 $\mu \mathrm{M}$ standard (line at about 0.8 counts) and sample are shown.

\subsection{Example: verification of analytical results with an unexpected variability during the online determination of ammonium and phosphate}

The techniques suggested above were used to improve the reliability of data gained of the online measurements of a new sequential injection analysis-based ammonium and phosphate analyser. This analyser is used to determine nutrients during campaigns on the North Sea and the Wadden Sea.

The example described here is an excerpt of a dataset gained during a three-week campaign on the North Sea in summer 2005. Part of this campaign was a transect from Buesum to Helgoland at July the 9th during which the results of the online determinations of both nutrients showed an unexpected variability. The expected nutrient distribution of such a transect includes an increase of the nutrient concentration roughly correlated to the distance to the shore and comparably small inhomogeneities on the high seas.

However, Figures 3 and 4 indicate either a very uneven nutrient distribution which does only remotely resemble the expected nutrient distribution or a problem with the sequential injection analysis system and the online sampling system. To eliminate analytical errors, all data collected during that transect was reviewed using the method described above.

The first step of this review is shown in Figures 3 and 4 , in which the online sample as well as the standards are plotted against the time. In both graphs, the blank as well as the standard are stable during the whole period of more than five hours. This leads to the assumption that the performance of the SIA system was stable over the whole time period. Any change in the performance of the SIA system would have also influenced the determination results of the blank and/or the standard.

During the second step of the review, the raw data of the respective time period is analysed (extract in Figures 5 and 6) to exclude erroneous results due to, for example, air bubbles in the sample. These air bubbles can occur due to a high

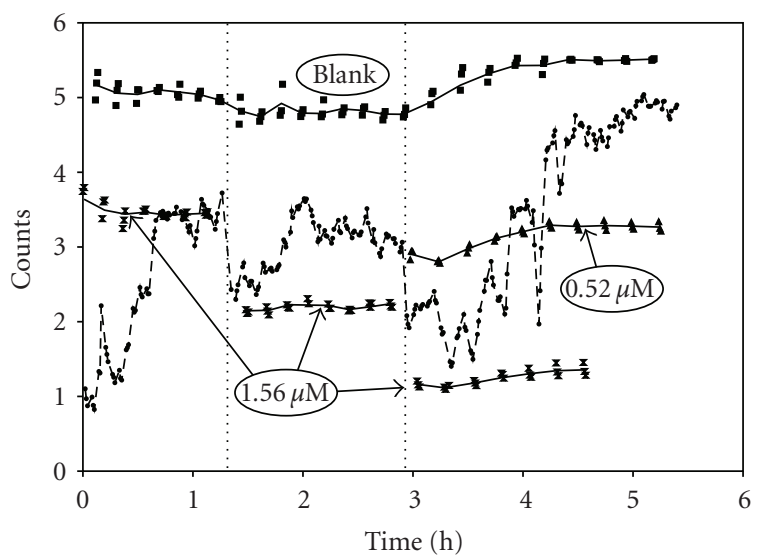

Figure 4: Phosphate date gained contemporaneously to the ammonium data displayed above. The vertical lines indicate the points in time when the sensitivity of the system was changed by changing the sample volume [11]. Blank (top line), $0.52 \mu \mathrm{M}$ and $1.56 \mu \mathrm{M}$ standard are shown next to the sample.

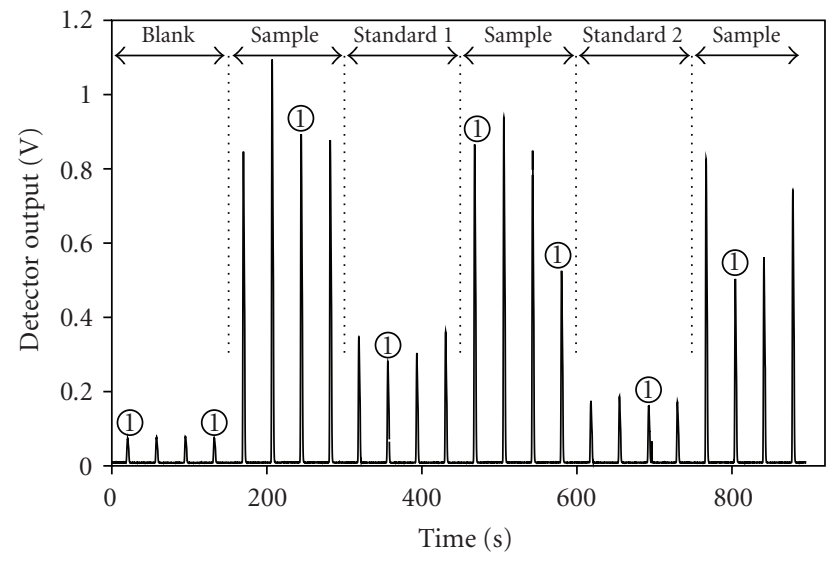

FIGURE 5: Raw data of all three ammonium channels gained during the same time as the data shown in Figure 3. The peaks marked with 1 are from the same "channel." The channels are slightly different and are calibrated independently.

oxygen concentration in the water caused by high algal primary production during sunny days. Neither the raw phosphate nor the ammonium data did show any irregularities.

The third and last step of such a review would be the comparison of manually collected and pretreated samples with the online sample. However, due to the assumed inhomogeneity of the water body and the proven inertness of the sampling and sample pretreatment system (a circular pump and a cross-flow filter), the manual samples were taken from the filtrate stream as indicated in Figure 7. These seven minutes pooled samples were integrated into the SIA system using a former unused valve port. The results of these determinations are shown together with the online data in the Figures 8 and 9. Together with the legitimate assumption that neither the pumping nor the filtration did have a that significant effect on the sample, it can be proposed that there may 


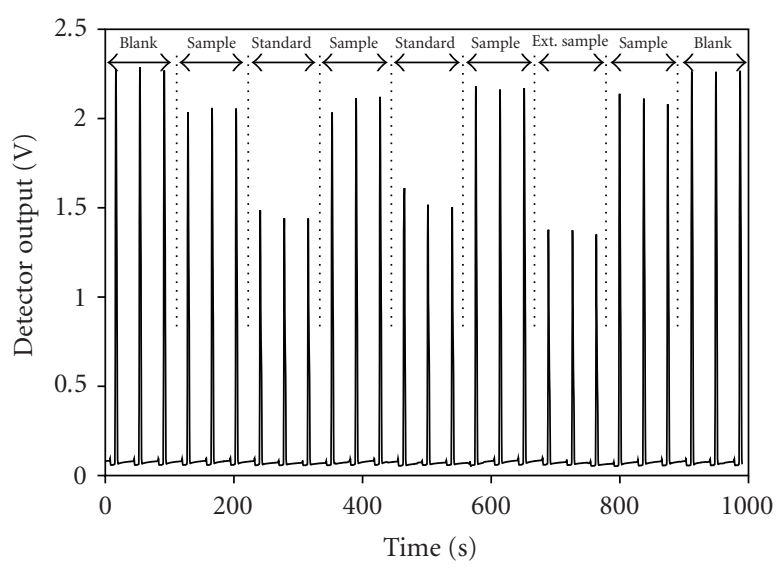

FIgURE 6: Raw data gained from the phosphate detector.

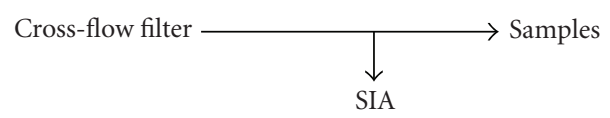

FIgURE 7: Offline samples were taken from the filtrate stream.

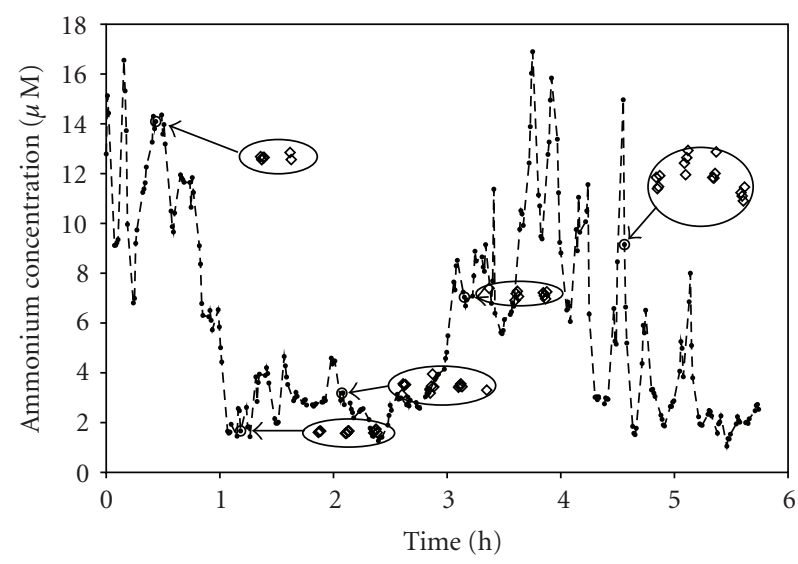

FIGURE 8: Data gained with all three ammonium "channels" combined with the results of the offline samples. The offline samples were determined with the same SIA system up to an hour after online determination. The differences between the online samples (dots) and the offline samples (diamonds) can be explained with the high variability of the ammonium concentration in the sample stream which is averaged by the higher sample volume and the sampling time (about seven minutes) for the offline samples.

occur high variations in the concentration of ammonium in the open sea.

It was found that the unexpected high variability of the concentration of ammonium (and on a smaller scale also phosphate) was most probably connected to the patchy bloom of the heterotroph plankton Noctiluca which discharges high amounts of ammonium and phosphate during cell lysis [15].

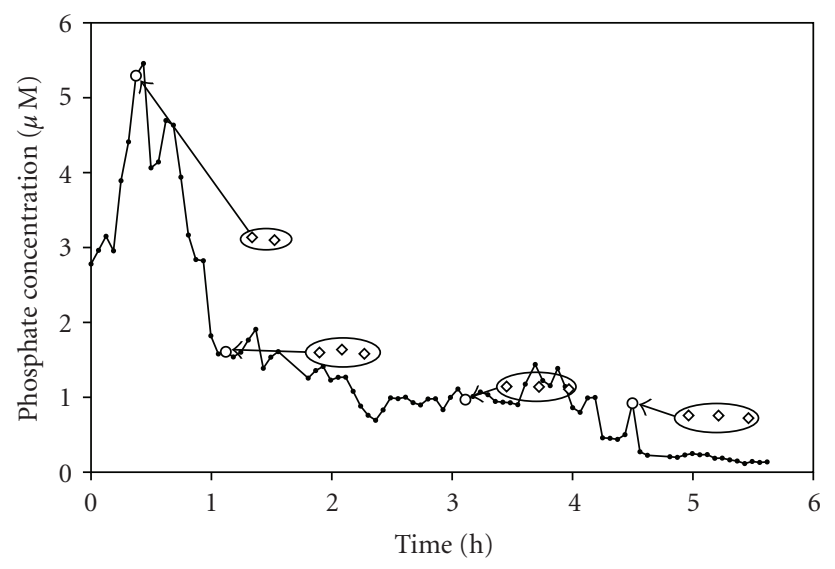

Figure 9: Phosphate data in $\mu \mathrm{M}$ calculated from the values indicated in Figure 4. Additionally, offline samples (diamonds) are integrated into the diagram. The arrows point to the theoretically corresponding online samples with the same restrictions as explained in Figure 8.

\section{CONCLUSIONS}

While all flow techniques are more or less suitable for online analysis systems, the sequential injection analysis (SIA) is especially qualified for online applications. Unlike all other flow techniques, the SIA integrates the ability to perform quality assuring measures in an automated manner without any supplementary devices (e.g., valves or autosamplers). This leads to analytical systems that are more portable than comparable systems which makes these systems especially suitable for monitoring applications in remote locations or on ships.

\section{REFERENCES}

[1] A. Aminot and R. Kérouel, "Assessment of heat treatment for nutrient preservation in seawater samples," Analytica Chimica Acta, vol. 351, no. 1-3, pp. 299-309, 1997.

[2] A. Aminot, D. S. Kirkwood, and R. Kérouel, "Determination of ammonia in seawater by the indolphenol-blue method: evaluation of the ICES NUTS I/C 5 questionnaire," Marine Chemistry, vol. 56, no. 1-2, pp. 59-75, 1997.

[3] R. M. Holmes, A. Aminot, R. Kérouel, B. A. Hooker, and B. J. Peterson, "A simple and precise method for measuring ammonium in marine and freshwater ecosystems," Canadian Journal of Fisheries and Aquatic Sciences, vol. 56, no. 10, pp. 1801$1808,1999$.

[4] G. Kattner, "Storage of dissolved inorganic nutrients in seawater: poisoning with mercuric chloride," Marine Chemistry, vol. 67, no. 1-2, pp. 61-66, 1999.

[5] M. Sliwka-Kaszyńska, A. Kot-Wasik, and J. Namieśnik, "Preservation and storage of water samples," Critical Reviews in Environmental Science and Technology, vol. 33, no. 1, pp. 31-44, 2003.

[6] J. E. Dore, T. Houlihan, D. V. Hebel, G. Tien, L. Tupas, and D. M. Karl, "Freezing as a method of sample preservation for the analysis of dissolved inorganic nutrients in seawater," Marine Chemistry, vol. 53, no. 3-4, pp. 173-185, 1996. 
[7] P. M. Burke, S. Hill, N. Iricanin, C. Douglas, P. Essex, and D. Tharin, "Evaluation of preservation methods for nutrient species collected by automatic samplers," Environmental Monitoring and Assessment, vol. 80, no. 2, pp. 149-173, 2002.

[8] P. C. F. C. Gardolinski, G. Hanrahan, E. P. Achterberg, et al., "Comparison of sample storage protocols for the determination of nutrients in natural waters," Water Research, vol. 35, no. 15 , pp. $3670-3678,2001$.

[9] A. J. Lyddy-Meaney, P. S. Ellis, P. J. Worsfold, E. C. V. Butler, and I. D. McKelvie, "A compact flow injection analysis system for surface mapping of phosphate in marine waters," Talanta, vol. 58, no. 6, pp. 1043-1053, 2002.

[10] C. Frank, F. Schroeder, R. Ebinghaus, and W. Ruck, "A fast sequential injection analysis system for the simultaneous determination of ammonia and phosphate," Microchimica Acta, vol. 154, no. 1-2, pp. 31-38, 2006.

[11] C. Frank, F. Schroeder, R. Ebinghaus, and W. Ruck, "Using sequential injection analysis for fast determination of phosphate in coastal waters," Talanta, vol. 70, no. 3, pp. 513-517, 2006.

[12] O. Elsholz, C. Frank, B. Stachel, H. Reincke, and R. Ebinghaus, "Sequential injection standard addition for on-line measurement of mercury in the river Elbe," Analytica Chimica Acta, vol. 438 , no. 1-2, pp. 251-258, 2001.

[13] R. Kérouel and A. Aminot, "Fluorometric determination of ammonia in sea and estuarine waters by direct segmented flow analysis," Marine Chemistry, vol. 57, no. 3-4, pp. 265-275, 1997.

[14] F. Wei, Z. Wu, and E. Ten, "The determination of trace amounts of phosphate in natural-water by flow-injection fluorimetry," Analytical Letters, vol. 22, no. 15, pp. 3081-3090, 1989.

[15] S. Montani, S. Pithakpol, and K. Tada, "Nutrient regeneration in coastal seas by Noctiluca scintillans, a red tide-causing dinoflagellate," Journal of Marine Biotechnology, vol. 6, no. 4, pp. 224-228, 1998. 


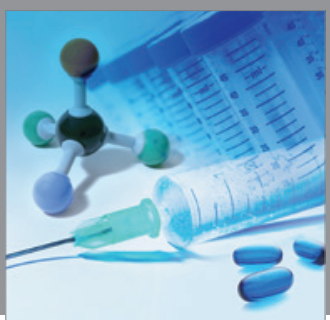

International Journal of

Medicinal Chemistry

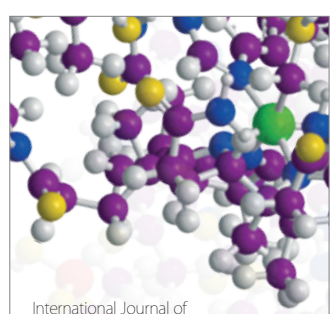

Carbohydrate Chemistry

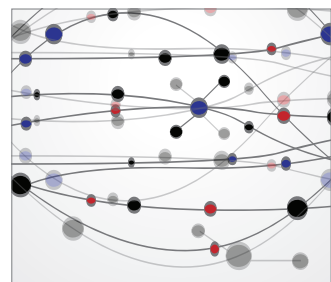

The Scientific World Journal
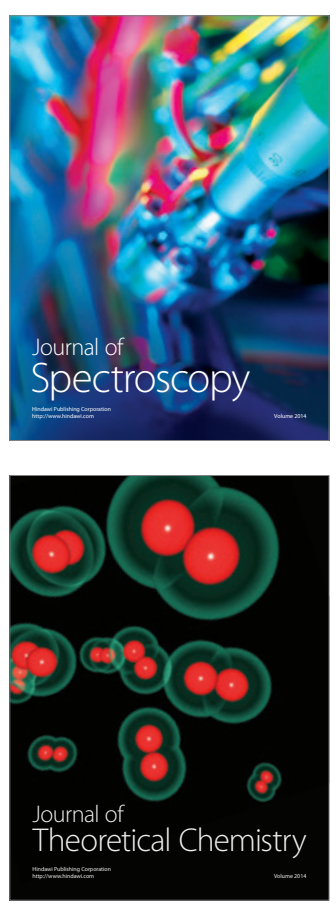
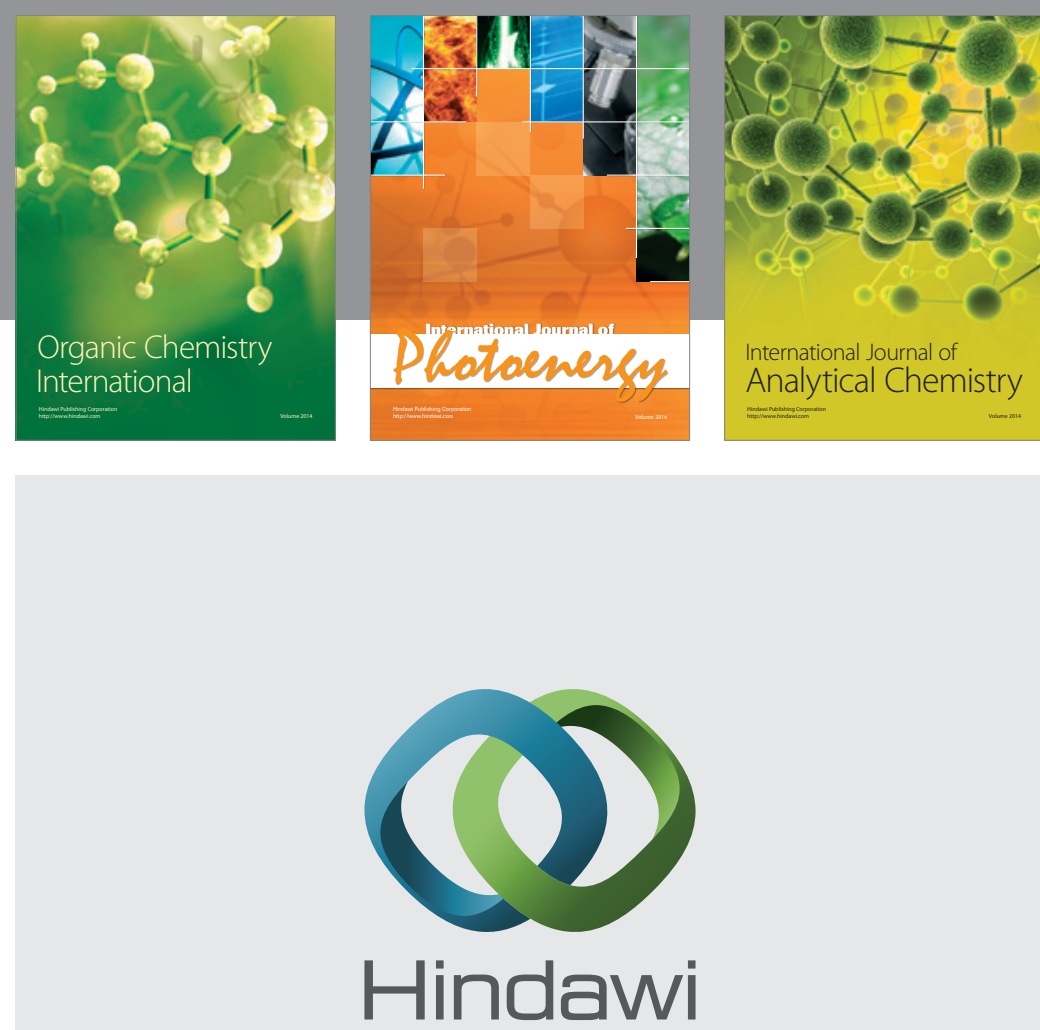

Submit your manuscripts at

http://www.hindawi.com
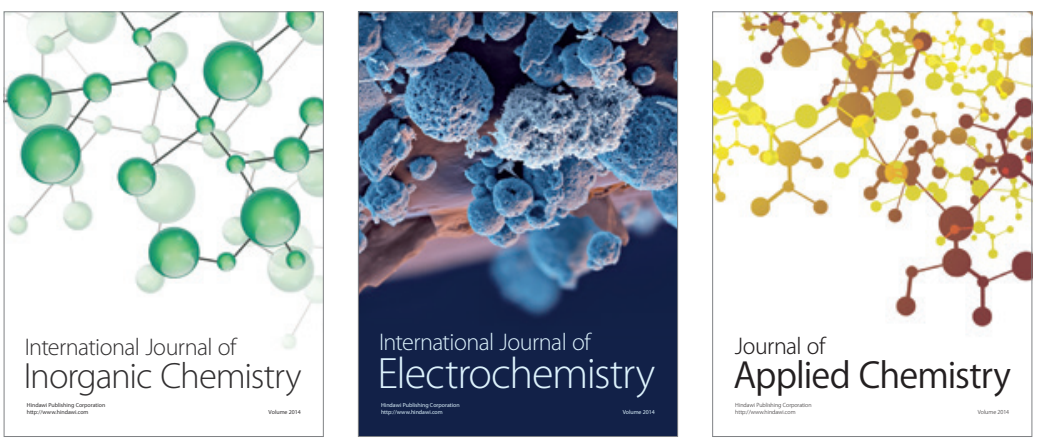

Journal of

Applied Chemistry
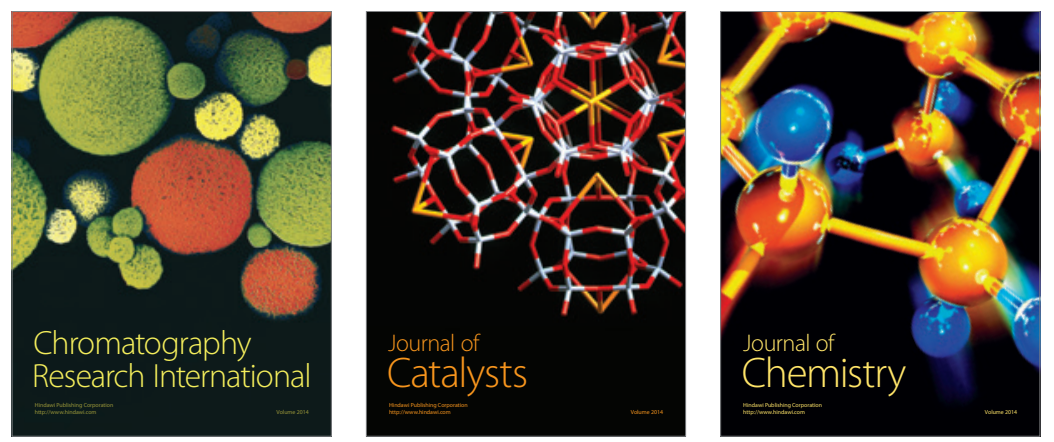
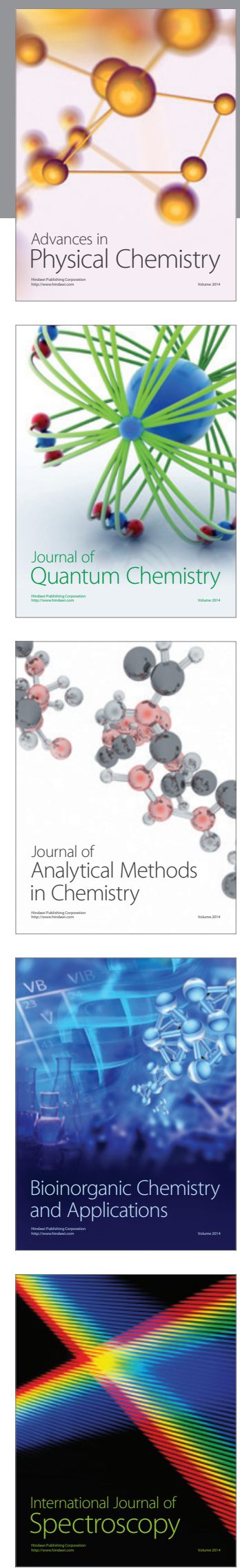